\title{
ASSISTENNCIA DE ENFERMAGEM DOMICILIAR EM EQUIPE MULTIPROFISSIONAL APÓS O ÓBITO DO PACIENTE ${ }^{1}$
}

\author{
ATTENDENCE OF HOUSE NURSING IN AFTER PATIENT'S DEATH
}

\section{ASISTENCIA DE ENFERMERÍA DOMICILIAR EN EQUIPO MULTIPROFESIONAL} DESPUÉS DE LA DEFUNCIÓN DEL PACIENTE

\author{
Sonia Silva Marcon ${ }^{2}$ \\ Alessandra Ferreira S. Rossini ${ }^{3}$ \\ Edlene Loureiro Aceti ${ }^{4}$
}

\begin{abstract}
RESUMO: Trata-se de um relato sobre a experiência de continuação da assistência domiciliar à família após a morte do paciente que determinou o início da assistência. $O$ presente artigo apresenta os critérios utilizados para incluir uma familia no "Serviço de Assistência Domiciliar às Familias de Pacientes Crônicos do HUM"; bem como as discussōes surgidas e os sentimentos experienciados pela equipe ante a possibilidade/proposta de continuação da assistência. Relata ainda a vivência experienciada pelos visitadores por ocasiāo das primeiras visitas após o óbito: e por fim, ressalta a importância da continuidade da assistência, com base nos relatos das manifestações verbais da familia e na avaliação dos membros da equipe. Os autores acreditam que devido ao fato da assistência à familia ainda se constituir em um tema pouco explorado, discussões que possam contribuir de alguma forma para a consolidação de sua prática devem ser viabilizadas $e$ incentivadas.
\end{abstract}

PALAVRAS-CHAVE: Familia - Assistência - Pós-óbito - Atuação multiprofissional

\begin{abstract}
This is report about an experience of continuation of home assistance to families after the patient's death who had determined the beginning of assistance. The present article shows the criteria used to provide a family with an "Assistance service and support to families of chronical patients of HUM" as well as discussions emerged and feelings experienced by the team when subjected to the possibility / proposal of the continuation of assistance. Furthermore the article considers the visitor's reaction at first visit made after death and finally it also presents the importance of continuation of assistance based on reports of verbal manifestation of the family and on evaluation of team members. The authors believe that due to the fact that the assistance to the family is still regarded as a topic which has been very little explored, discussions that might contribute somehow to the consolidation of its practicability must be made possible and stimulated.
\end{abstract}

KEYWORDS: Family - Assistance - Death - Multiprofessional performance

\footnotetext{
1 Trabalho desenvolvido por membros do NEPAAF (Núcleo de Estudos, Pesquisa, Assistência e Apoio à Familia) da Universidade Estadual de Maringá (UEM). Projeto original financiado pelo CNPq.

${ }^{2}$ Professora do Departamento de Enfermagem da UEM. Doutora em Filosofia da Enfermagem.

${ }^{3}$ Psicóloga. Participante do Projeto: Serviço de Assistência e Apoio às Familias de Pacientes Crônicos do Hospital Universitário.

${ }^{4}$ Acadêmica do Curso de Enfermagem da UEM. Bolsista de Extensão.
} 
RESUMEN: Se trata de una exposición sobre la experiencia de continuación de la asistencia domiciliar a la familia después de la muerte del paciente que determinó el inicio de la asistencia. El presente artículo muestra los criterios usados para incluir una familia en el "Servicio de Asistencia Domiciliar a las Familias de Pacientes Crónicos del HUM"; asi como las discusiones surgidas y los sentimientos experimentados por el equipo delante de la posibilidad/propuesta de confinuación de la asistencia. Demuestra todavía la vivencia experimentada por los visitadores por ocasión de las primeras visitas después de la defunción: y por fin resalta la importancia de la continuidad de la asistencia, con base en los informes de las manifestaciones verbales de la familia y en la evaluación de los miembros del equipo. Los autores creen que devido al hecho de la asistencia a la familia todavia se constituya en un tema poco explorado, discusiones que puedan contribuir de alguna forma para la consolidación de su práctica deben ser viabilizadas e incentivadas.

PALABRAS CLAVE: Familia - Asistencia - Post defunción - Actuación multiprofesional

\section{INTRODUÇÃO}

Nos últimos anos, a enfermagem brasileira vem assistindo a uma mudança de paradigma referente à orientação metodológica utilizada no desenvolvimento da pesquisa , o que tem suscitado, por conseguinte, uma mudança também em seu foco de investigação. Tudo isso tem ocorrido paralelamente a uma crescente preocupação com a necessidade de instituir e subsidiar mudanças em sua prática assistencial.

O estabelecimento da familia como objeto de trabalho constitui exemplo de como a prática da enfermagem tem sido influenciada pelo paradigma emergente, que é constituído por uma visão caracterizada, segundo Capra (1991), por "palavras como orgânica, holistica e ecológica".

Esta definição/opção pela familia no entanto está sendo gradual. Ao mesmo tempo que a enfermagem foi-se dando conta da impossibilidade de compreender as situações de saúde e doença a partir de um modelo unicausal, ela também foi compreendendo que o comportamento do ser humano, seja em situações de saúde ou de doença, é influenciado pelo contexto cultural, social e histórico, surgindo assim a necessidade de uma aproximação com outras ciências.

Ante esta perspectiva, a familia passou a se constituir em objeto de investigação ao mesmo tempo que se tornou também objeto do trabalho, e, portanto, da assistência de enfermagem. Ou seja, implantou-se a convicção de que é praticamente impossivel assistir ao indivíduo (doente ou sadio) de forma completa quando não se considera pelo menos o seu contexto mais próximo, que é a familia à qual ele pertence, pois vários estudos têm demonstrado que a familia tanto pode ser entendida como fonte de saúde como de doença para seus membros (Bub et al, 1994). 
A familia, portanto, além de ser agente do cuidado de seus membros, também deve ser considerada como objeto de cuidados dos profissionais de enfermagem, os quais vislumbram a necessidade de uma atuaçäo multiprofissional. Embora o estado de saúde da família e a de seus membros sejam diferentes, estão interligadas. É sabido que a situação de saúde/doença de um dos membros afeta toda a familia. Elsen (1954), por exemplo, enfatiza quanto uma hospitalização ou uma doença grave pode alterar a dinâmica familiar, já que os papéis precisam ser redimensionados e o estresse permeia as relações interpessoais, gerando, inclusive, uma situação de crise na unidade familiar. Este fato por si só já configura a necessidade de assistência da família.

De qualquer forma, os profissionais que trabalham na área da saúde, de certa forma, têm sua atuação restrita ao momento em que ocorre sua intersecção com a doença, ao passo que cabe à familia a continuidade do cuidado até a completa recuperação do paciente. Quando esta não é possivel, a familia também arca com a extensão crônica da doença e suas conseqüentes seqüelas.

Tendo como principio o fato de a familia constituir uma unidade de cuidado para seus membros, cabe aos profissionais de saúde refletir sobre a assistência a ser prestada à familia, no sentido de ajudá-la, da melhor forma possível, no desempenho de sua tarefa de cuidar. Neste sentido, ela deve ser concebida como co-participante do processo de cuidar em todos os momentos, inclusive em situações de morte iminente ou real. Cabe, pois, aos profissionais identificar as situações nas quais ela precisa ser melhor assessorada.

Vários estudos já foram realizados, inclusive envolvendo a familia, com pacientes em fase terminal, e seus resultados têm demonstrado a grande fragilidade da familia como um todo, e por conseguinte a necessidade da mesma ser cuidada neste momento de "crise", com vistas a fortalecê-la no enfrentamento da situação de morte de seu ente querido. Contudo, os estudos e os relatos da experiência vivenciada pela familia após o óbito de um de seus membros ainda são escassos. De forma geral, se observa que, com o óbito, os profissionais da área da saúde se afastam. É como se já houvessem cumprido, sem êxito, sua missão, qual seja a de salvar vidas.

Assim, com o óbito, até mesmo aquelas familias de certo modo privilegiadas por estarem sendo assistidas no enfrentamento da crise desencadeada pela situação de morte iminente são, via de regra, "abandonadas". No entanto, com o fato consumado só os problemas do paciente chegam ao fim, ao passo que os da familia continuam, além de surgirem novos (Iuchno e Silva, 1995). E isto ocorre em várias esferas, inclusive em relação à saúde, que pode ser abalada em maior ou menor grau, dependendo dos suportes e recursos da familia. 
Diante do exposto, propusemo-nos a desenvolver o presente artigo com o objetivo de relatar a experiência vivenciada ao dar continuidade à assistência domiciliar a duas familias de pacientes que foram a óbito.

\section{METODOLOGIA}

Trata-se de um relato da experiência teórico-prática vivenciada por participantes do Nepaaf (Núcleo de Estudos, Pesquisa, Assistência e Apoio à Familia) durante o segundo semestre de 1997, junto a familias de pacientes crônicos residentes em Maringá - PR, atendidos no Hospital Universitário (HUM) . Experiência teórica porque envolve as discussōes de um grupo a partir de suas concepções sobre a assistência profissional; e experiência prática porque adquirida a partir do acompanhamento e assistência prestada às familias no domicilio.

A experiência em questão foi vivenciada diante da situação de morte na familia. Os dados foram coletados basicamente em duas fontes de informações: as transcrições das reuniōes do Nepaaf (que eram gravadas e transcritas literalmente) e os relatos contidos nos diários dos visitadores, os quais são feitos individual e rotineiramente após a realização de cada visita.

$\mathrm{Na}$ interpretação dos dados, adotou-se o referencial de análise de conteúdo segundo Bardin, (1994). Ou seja, após a leitura e escuta flutuante das transcrições das reuniōes e dos relatos contidos nos diários dos visitadores, os dados foram refletidos, visando a organização da experiência em fases que possibilitassem a compreensão tanto do desejo da familia em continuar ou não sendo assistida quanto da condição do grupo em prestar assistência às familias que vivenciam a situação de óbito.

Por se tratar de uma atividade que envolve seres humanos, observamos os aspectos éticos disciplinados pela Resolução 01/88, do Conselho Nacional de Saúde / MS, assegurando às familias inscritas no Programa de Assistência informaçōes sobre os objetivos do mesmo, o livre consentimento, a liberdade de desistir da participação, se em qualquer momento assim desejassem, além de garantia de anonimato nas divulgaçōes sobre os resultados obtidos com a experiência.

\section{RELATANDO A EXPERIÊNCIA}

O "Serviço de Assistência e Apoio às Familias de Pacientes Crônicos do HUM" é um projeto que busca, através da integração dos princípios de ensino, pesquisa e extensão, proporcionar uma melhoria na qualidade de vida e na saúde das familias assistidas. O mesmo é desenvolvido por acadêmicos dos 
cursos de enfermagem e farmácia, enfermeiros e psicólogos. Com o intuito de estabelecer a interação, cada família é assistida por uma dupla de alunos sob a supervisão do enfermeiro ou do psicólogo. Cada dupla se responsabiliza pela assistência de duas ou no máximo três familias.

Alguns critérios são utilizados na definição das familias a serem assistidas pelo projeto: ter um membro da familia portador de doença crônica e este ter se submetido a uma internação recente no HUM; a familia residir no município de Maringá e, após esclarecimento sobre os objetivos do projeto, concordar em ser incluida no mesmo.

As atividades do projeto são desenvolvidas prioritariamente no domicilio, uma vez que o indivíduo portador de doença crônica é visto pelo grupo apenas como porta de entrada à familia, a qual constitui o objeto real da assistência.

Como parte da estratégia, são utilizados alguns formulários elaborados especificamente para o projeto, entre os quais citamos: o instrumento de coleta de dados da família, o plano de assistência à familia, o relatório de visita domiciliar e o diário do visitador.

No diário do visitador, é registrada a reflexão pessoal em termos de contribuição da assistência prestada na melhoria da saúde familiar. Os relatos contidos nestes diários servem para direcionar a assistência, subsidiar a coleta de dados para o projeto de pesquisa e dar oportunidade aos visitadores de vislumbrarem a integração entre a teoria e a prática da assistência no domicilio.

O trabalho estava sendo desenvolvido dentro dos padröes previstos (já que a própria dificuldade em abordar a familia e não apenas o individuo doente já era, de certa forma, esperada), quando uma nova situação trouxe à tona uma série de questionamentos motivados pela dúvida sobre a continuação ou não da assistência à familia após o óbito do paciente.

Em função de não existir uma decisão concreta e inclusive do tempo que se levou até que a mesma fosse tomada, já que optamos por discutir esta questão no grupo de estudo, três familias deixaram de ser assistidas por ocasião do óbito. A decisão pela continuidade da assistência coincidiu com a entrada no grupo de uma psicóloga, o que inclusive proporcionou maior segurança aos visitadores, que acreditavam estar assim melhor assessorados, além de poderem prestar uma assistência mais adequada à situação em questão.

Vale ressaltar nossa convicção de que, para assistir à familia de modo adequado, independentemente de uma situação de óbito, dada a diversidade de suas necessidades, se faz necessária uma atuação multiprofissional, o que ainda estamos procurando concretizar. Atualmente, além da enfermagem, psicologia e farmácia que já atuam no projeto, estão sendo mantidos contatos com profissionais das áreas de odontologia, medicina e educação física. 


\section{Apresentando as familias}

Os dados deste artigo se referem à experiência vivenciada em relação à assistência prestada a duas familias. Nos dois casos o membro da família acometido de doença crônica era mulher. Maria era uma senhora de 66 anos, viúva, portadora de seqüela de acidente vascular cerebral, hipertensão arterial severa e insuficiência cardiaca congestiva e morava com uma filha e uma neta de 1 ano. Na mesma cidade ainda moram mais quatro filhos, todos casados. Esta paciente era cuidada durante o dia por uma moça contratada para tal. No meio da tarde, uma das filhas se deslocava até sua casa e assumia o cuidado até que a irmã (que morava com a mãe) chegasse do serviço. Vera, por sua vez, tinha 48 anos, era portadora de diabetes mellitus II, hipertensão arterial severa e neoplasia a esclarecer; morava com o marido e um filho de 22 anos portador de doença mental. Ela era cuidada pelo esposo, que já estava desempregado havia algum tempo. Seu filho de tempos em tempos sumia de casa, inclusive estava desaparecido quando a mãe morreu.

\section{Apresentando os dados}

Para efeitos didáticos, a experiência está sendo dividida em três partes:

1) Discutindo a continuidade ou não da assistência à família após o óbito do paciente no grupo de estudo.

O continuar ou não a assistir à familia após o óbito foi inicialmente discutido em reunião do Nepaaf, e os aspectos apresentados neste subitem referem-se às reações dos membros deste grupo, o qual é constituido tanto por pessoas com experiência prática por atuarem no referido serviço, como por outras que também contribuiam, porém em nivel teórico, uma vez que nāo participavam do serviço assistencial.

Com relação a este questionamento, encontramos posturas distintas dentro do grupo. Alguns eram favoráveis à continuidade, houve quem demonstrasse dúvida e outros delegaram a decisão para a própria familia.

$\mathrm{Na}$ opinião dos favoráveis, a continuidade se justificava pelo vínculo estabelecido com a familia

"Se tá na família tem que continuar... você criou um vínculo com essa pessoa sem delimitar a saída, agora de repente, você quebra esse vínculo só porque o outro morreu..." (Professora de Enfermagem)

e também pela conscientização de que este representa um momento de crise para a familia,

"... mas a família deve continuar sendo apoiada, até porque a perda de um dos membros é uma situação delicada..." (Psicóloga da Secretaria de Saúde) 
visto que a mesma fica desestruturada com a perda, pois muitas vezes a rotina da familia é estruturada em função dos cuidados a serem prestados ao indivíduo doente.

"... ela tá desestruturada, ela precisa desse apoio que você deu anteriormente..." (Professora de Enfermagem).

Ao ressaltarem sua opinião, alguns membros relembraram que para o grupo o individuo doente representava apenas a porta de entrada na familia, pois o objetivo do projeto era a melhoria da qualidade de vida e saúde da familia como um todo.

"... você vai até a família pela pessoa, mais quando você entra $e$ começa a atender, você não atende a pessoa, você atende a família... se o doente morre, o doente era também um dos que nós estariamos atendendo... então a gente tem que dar continuidade a esse atendimento..." (Professora de Enfermagem).

Apesar deste norteamento, algumas pessoas mostraram-se em dúvida com relação à validade desta continuação:

" $E$ ver como é que era o plano de assistência para essa família, se estava centrado única e exclusivamente no paciente ou se ele estava voltado para a família..." (Professora de Enfermagem)

e outras acharam por bem deixar a decisão sobre a continuidade da assistência para a própria familia, ressaltando que, se esta aceitasse, ela se sentiria mais à vontade para se expressar e expor seus sentimentos.

"A princípio eu responderia assim: vamos consultar a familia... Se ela ainda aceita que a gente continue" (Professora de Enfermagem).

"Não, não, eu acho que precede, a família tem que decidir se quer você lá dentro ou não. Porque se ela disser sim ela vai colocar para fora o que ela quer..." (Psicóloga da Secretaria de Saúde).

Acreditamos que se colocar disponivel e ao mesmo tempo permitir que a familia tome a decisão é a estratégia mais correta, pois se por um lado este é um momento de crise para a familia é preciso que se reconheça que as reaçōes não são unânimes nem entre os membros de uma mesma unidade familiar. $\dot{E}$ preciso, portanto, respeitar suas características, seu ritmo, suas forças e seus recursos, bem como os sentimentos experienciados por cada familia. É provável que alguns membros se sintam melhor se existir alguém com quem dividir e compartilhar as lembranças dos momentos dolorosos vividos antes de se concretizar a perda. Se este for o caso, esta presença pode facilitar uma aceitação gradativa, contribuindo para superação do choque e do pesar vividos (Kubler-Ross, 1994). 
Com relação a esta questão, vale salientar que Rogers e Rosemberg (1977) afirmam que normalmente o problema que incomoda emerge na fala das pessoas; sendo assim, só o fato da pessoa poder exteriorizar o que a está perturbando já ajuda a resolvê-lo.

\section{2) Os sentimentos experienciados em relação à visita.}

A primeira visita após o óbito despertou sentimentos controversos entre os visitadores. Mesmo antes de sua realização, os visitadores relataram sentir insegurança e ansiedade, especialmente por se tratar de uma situação nova e portanto não saberem como seriam recebidos, ou mesmo como deveriam agir frente à situação de morte de um parente.

"... fiquei pensando: como iria me comportar, como iria falar sobre isso e qual seria o seu estado diante do falecimento recente da esposa" (Acadêmica de Enfermagem 1).

"Até chegarmos ao local fui perguntando-me como seria a recepção após um fato tão triste, o que deveria e o que não deveria falar em tal situação, se aceitariam que continuássemos fazendo visitas" (Acadêmica de Enfermagem 2).

O lidar com a morte também é um processo dificil para os profissionais que atuam na área da saúde, pois estes são influenciados culturalmente pelo fato de pertencerem a uma categoria profissional caracterizada pela detenção de um "poder" relativo à manipulação de recursos técnicos, tendo em vista a cura do paciente ou pelo menos a melhora dos sintomas decorrentes da doença (Pinkus, 1988), ou seja, conforme citado por Boemer, Veiga, Mendes, Valle (1994), desde o inicio de sua formação esses sentem-se compromissados com a vida e experimentam sentimentos de gratificação diante da cura, ou pelo menos com a diminuição do sofrimento. No entanto, quando necessitam lidar com situaçōes que envolvem a morte, sentem-se despreparados e a tendência mais frequente é a de procurarem se afastar de situaçőes desta natureza.

Além disso, existia a preocupação com a própria condição de saúde das pessoas mais próximas

"Estava ansiosa por saber como ela estava, pois, quando a mesma deu-me a noticia por telefone, parecia inconsolavel e pedindo ajuda, ainda que entrelinhas" (Acadêmica de Enfermagem 2).

No decurso da primeira visita, sensações e sentimentos negativos foram vivenciados por alguns visitadores, que se sentiram como invadindo a privacidade da familia

"... achei muito estranho, pois a dor e o sofrimento da família, poderiam estar sendo invadidos por nós..." (Enfermeira) 
e isto inclusive desencadeou sentimentos de culpa.

"Achei difícil dialogar sobre alguém que não está presente fisicamente, que já morreu. Parece que ela ficou a semana toda planejando o que ia falar, e às vezes chorava, provocando em mim um sentimento de culpa por estar lhe causando dor e sofrimento" (Enfermeira).

Após o término da visita, era quase que inevitável não realizar uma avaliação sobre o estado da familia após a perda

"Fiquei feliz em perceber que apesar da perda, eles estão tocando a vida para frente e mostraram-se conscientes e preocupados em se reestruturar nesta nova situação de vida" (Psicóloga).

e também sobre os sentimentos experienciados.

"O fato de poder ajudar alguém na hora de enfrentar uma dificuldade como a vivenciada por esta familia, deixou-me muito bem..." (Psicóloga).

Deixar a familia falar livremente e conversar com ela foi interpretado como de suma importância quando o objetivo é ajudar a familia a superar a dor.

"Conversar pode em primeiro momento não parecer, mas é válido, pois as pessoas colocam para fora um pouco da tristeza e do vazio que lhes toma conta pela perda de um ente querido" (Ac. Enf. 2).

Nesta avaliação também foi possivel identificar que uma das visitadoras não se sentiu à vontade em dar continuidade à assistência:

"Não vi o que eu poderia estar fazendo para ajudar aquela mulher. Ela não tinha nenhum problema de saúde, mas sim problemas com a irmã... . Portanto, a única pessoa que poderia estar orientando e ajudando era a própria psicóloga" (Ac. Enf. 3).

Neste caso específico, acreditamos que o fato de a acadêmica não estar totalmente entrosada com a familia e, inclusive por motivos particulares, ter faltado às duas primeiras visitas realizadas após o óbito, contribuiu para que a mesma tivesse este tipo de posicionamento. Enquanto grupo, acreditamos que trabalhar junto com uma psicóloga, especialmente durante a graduação, pode representar uma oportunidade impar para que profissionais e futuros profissionais ampliem seus conhecimentos e aprendam a trabalhar em equipe, 0 que não é, de modo algum, dividir tarefas que devam ser executadas isoladamente: esta é minha parte, está é sua parte.

A acadêmica também justificou sua posição considerando a condição de saúde da familia: 
"Sei que o objetivo do projeto é dar assistência não só ao paciente, mas sim à familia também; porém se apenas o paciente era doente $e$ os seus familiares são saudáveis, não vejo a necessidade de continuarmos realizando as visitas..." (Ac. Enf. 3).

O fato de nós, profissionais de saúde, não enxergarmos a necessidade de assistência a uma familia que passa por uma situação de perda está relacionada à dificuldade que temos em atuar na saúde. Isto, de certo modo, é compreensivel, pois somos formados para atuar na doença, ou seja, no ponto de intersecção entre a saúde e a doença. Isto leva-nos a uma dificuldade concreta de enxergar nosso papel junto à familia, na manutenção de sua saúde. Além de que, ainda temos muitas dificuldades em centrar nossas atividades de assistência na familia, de modo especial quando um dos membros é doente, pois indiretamente muitas de nossas ações dirigem-se a esta pessoa. Nestes casos, com o óbito do individuo, aumenta a probabilidade de a familia como um todo passar a ser focalizada na perspectiva assistência.

3) Percebendo as reações da família frente à visita e frente à situação de óbito

A possibilidade de continuar sendo assistida também pode despertar na familia reações favoráveis ou contrárias. Alguns familiares ressaltaram em suas manifestaçōes o quanto essa continuidade poderia vir a ajudá-los nesse momento difícil

"Gosto que vocês venham aqui para a gente conversar, porque nós estamos precisando conversar, temos muito o que falar e vocês ficam ouvindo e conversando com a gente" (Filha 1 de Maria).

e inclusive manifestam o desejo de estender a assistência a outros membros.

"Acho que é uma boa idéia vocês fazerem visita para a minha irmã, como eu conheço bem ela, percebo que ela está desorientada e gostaria que vocês a ajudassem, vou entrar em contato com ela e dizer como me senti bem depois de conversar com vocês" (Fillha 1 de Maria).

Por outro lado, a familia também pode, diante de outras dificuldades, não perceber a visita como uma prioridade no momento.

"Não é desmerecendo o esforço de vocês e a preocupação, mas é que agora como eu fiquei sozinho, eu vou ter que procurar um emprego para poder me sustentar e pagar minha contas e depois que eu estiver trabalhando ficaria difícil vocês me encontrarem, vocês iriam perder muitas viagens, acho que isso não compensa para vocês, acho que o trabalho foi muito bom até aqui" (Esposo de Vera). 
A nova realidade imposta com a perda representa para os familiares o momento de reestruturação, pois têm que contornar a sensação de vazio ou de sentir-se desorientados.

"Estou um pouco desorientado quanto a várias coisas, por exemplo, às vezes não sei por onde começar o serviço... tá sendo difícil me adaptar, tenho que procurar pelo que fazer" (Filha 2 de Maria).

"Estou sentindo um vazio por dentro e sei que tenho que preencher, essa perda me deixou perdida no tempo e no espaço" (Filha 2 de Maria).

O estado de desorientação é facilmente percebido, pois, como afirmam Rezende et al., a perda através da morte é mais dolorosa em função da proximidade afetiva consangüínea, o que é caracterizado pelo sentir-se impotente, no sentido de não poder interferir ou reverter a perda.

A assistência no domicilio permite aos visitadores perceber reaçōes e sentimentos do familiares dentro de uma perspectiva totalmente nova, praticamente impossível de ser percebida em uma situação fora do domicilio. Ao abordarem esta questão, os visitadores ressaltam a "força" dos familiares

"Ela está aceitando o acontecimento apesar de ser muito difícil, está tentando ocupar seu tempo..." (Acadêmica de Enfermagem 2)

e passam inclusive a conhecer e valorizar as diferentes maneiras com que as pessoas reagem nestas situações, o que lhes possibilita uma compreensão inclusive do que representa cuidar de um membro doente durante vários anos.

"Parecia estar bem tranqüilo, consciente que o estado dela era bem avançado. E ainda falou que era a sua hora e que Deus sabe o que faz" (Acadêmica de Enfermagem 1).

Conhecer as diferentes formas e maneiras com que as pessoas lidam com a questão da morte constitui um dos pontos altos desta experiência. É bem verdade que num primeiro momento podemos inclusive nos chocar diante da variedade, mas enquanto profissionais e futuros profissionais não podemos deixar de respeitar e valorizar as diferenças culturais da família. $E$ isto ficou expresso nas falas dos visitadores.

"Penso que talvez as pessoas como ele, que têm muitos problemas, que leva uma vida com muitas dificuldades financeiras, de moradia, de conseguir emprego e até de doença, têm uma reação diferente com $o$ sofrimento. Vemos pessoas que procuram até a assistência de psicólogos após a perda de algum familiar próximo. Ele se mostrou bem, conversando sobre o assunto "sem problemas". Não estou aqui 
dizendo que ele não sofreu, mas penso que os sofrimentos tornam-se "banalizados". É como se ele fosse fazendo uso de mecanismos de defesa para continuar vivendo" (Acadêmica de Enfermagem 1).

"Mostrou-se uma pessoa forte, bem estruturada, que dispõe de mecanismos internos que ajudam na recuperação frente a esta nova situação" (Psicologa).

Outro ponto ressaltado pelos visitadores é o fato de os familiares precocemente já se preocuparem com outras questões emergentes, em função da nova situação.

"Está bem, mas demonstra preocupação por não conseguir reunir todos os irmãos para resolver o impasse do inventário e o destino da irmâ. (...) está tentando encaminhar as irmãs, ou pelo menos orientálas no melhor caminho" (Acadêmica de Enfermagem 2).

"Ele está bem "forte", tranqüilo e agora tem que se preocupar em arrumar emprego para garantir seu sustento" (Acadêmica de Enfermagem 1).

\section{CONCLUSÃO}

A análise dessa experiência - assistência à familia no domicilio após o óbito do paciente - nos permite concluir o quanto é relevante a continuidade desse acompanhamento. Deixar a familia falar, chorar, gritar, se necessário, deixar conversar, deixar que participe... Mas convém que fiquemos à disposição, pois o período de luto é longo e a assistência e apoio à familia são de suma importância nos dificeis meses que se seguem. Durante este periodo devemos tentar compreender suas necessidades, partilhando todos os sentimentos emergentes frente à perda. A tolerância dos sentimentos de raiva dirigidos a nós, ao falecido ou mesmo a Deus pode ajudar na aceitação da nova realidade sem culpas, ao passo que, se incentivarmos a repressão destes pensamentos pelo fato de os mesmos não serem aceitos socialmente, só estaremos contribuindo para o prolongamento do pesar, da vergonha e da culpa, o que poderá acarretar um comprometimento em nivel de saúde física e emocional.

Enquanto profissionais da área de saúde, ainda que com limitações, em situaçōes de óbito devemos tentar voltar a nossa atuação para a família. Acreditamos, no entanto, que centrar a assistência na familia constitui uma atividade ainda por ser aprendida, o que, sabêmo-lo, não ocorrerá de uma hora para outra, afinal foram anos e mais anos de assistência curativa e individualizada. 
O assistir à familia após o óbito do paciente é uma atividade que requer estudos, discussões, envolvimento e comprometimento por parte do profissional. Trata-se de uma nova modalidade de atuação dentro da área da saúde.

A vivência prática desta experiência na qualidade de prestador da assistência se revelou de grande importância no desenvolvimento e crescimento profissional; por outro lado, este tipo de assistência proporciona à família a oportunidade impar de exteriorizar e trabalhar a grande variedade de sentimentos experienciados, o que a familia sozinha levaria muito mais tempo para conseguir.

Vale salientar que a principio o constrangimento e receio frente ao fato é recíproco (familia e equipe de assistência), mas gradativamente a confiança e o envolvimento tornam-se fortes a ponto de os visitadores atuarem como suporte adequado à família em momentos de profunda dor e tristeza.

Acreditamos que a assistência à familia, na prática e em nossa realidade de Brasil, está apenas começando. Existe, portanto, um longo caminho a ser percorrido, no qual a necessidade de aprendizagem metodológica e estratégica sobre como lidar com este objeto de assistência é uma evidência e, em assim sendo, discussões como esta, que possam contribuir de alguma forma para a consolidação de sua prática, devem ser viabilizadas e incentivadas.

\section{REFERÊNCIAS BIBLIOGRÁFICAS}

1. BARDIN, L.. Análise de conteúdo. Trad. Luis Antero Reto e Augusto Pinheiro. Lisboa: Editora Jo, 1994.

2. BRASIL. Constituição Federal de 1988, cap.III, art. 205, 9 ed. Brasília: Icone, 1988.

3. BOEMER, M. R.; VEIGA, E. V..; MENDES, M. M. R.; VALLE, E. R. M. do. O Tema da morte: uma proposta de educação. R. Gaúcha de Enferm., Porto Alegre, v. 3, n. 1, p. 26-32, 1994.

4. BUB, L. I. R. et al. Marcos para a prática da enfermagem com familias. Florianópolis: Ed. UFSC, 1994. $195 \mathrm{p}$.

5. CAPRA, F.. O ponto de mutação. 5 ed. São Paulo: Cultrix, 1991.

6. ELSEN, I.. Concepts of health and illness and related behaviour among families living a Brasilian fishing village. San Francisco: UCSF, 1984. 301 p. Tese (Doutorado em Ciências de Enfermagem), University of California. 
7. IUCHNO, A. ; SILVA, R. P.. Terapia de uma familia enlutada em decorrência da enfermidade materna. III Conferência Ibero Americana sobre Familia. São Leopoldo, 1995. (publicação avulsa).

8. KUBLER-ROSS, E.. Sobre a morte e o morrer. São Paulo: Martins Fontes, 1994.

9. PINKUS, L.. Psicologia do doente. São Paulo: Paulinas, 1988.

10. REZENDE, A. L. M.; SANTOS, G. F.; CALDEIRA, V. da P.; MAGALHÃES, Z. R.. Ritos de morte na lembrança de velhos. R. Bras. Enferm., Brasilia, v. 48, n. 1, p. 7-16, 1995.

11. ROGERS, C.R. ; ROSENBERG, R.L.. A pessoa como centro. São Paulo: EPU/EDUSP, 1977. 